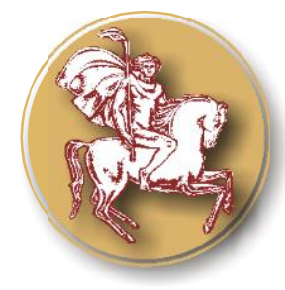

Trakia Journal of Sciences, No 4, pp 356-364, 2021

Copyright (C) 2021 Trakia University

Available online at:

http://www.uni-sz.bg

ISSN 1313-3551 (online)

doi:10.15547/tjs.2021.04.010

\title{
CONDITION AND DEVELOPMENT TRENDS OF WINE TOURISM IN BULGARIA (THE EXAMPLE OF FESTIVALS OF WINE AND FOLKLORE HERITAGE)
}

\author{
V. Zheleva, B. Stoykova* \\ Department of Regional Development, Faculty of Economics, Trakia University, Stara Zagora, \\ Bulgaria
}

\begin{abstract}
Tourism is one of the most significant sectors, generating major economic benefits. This makes it an important part of the economy in many parts of the world.

Tourism, as a means of developing the region, is closely tied to the development of the local economy. Wine tourism, in particular, turns out to be a significant tool for the development of Bulgaria. Considering the sector's importance, the goal of this study is to analyse the condition and development trends of this particular type of tourism in the country and in the region. The survey method includes statistical, historical, comparativedescriptive, and regional analysis. In a broader aspect, this study will contribute towards expanding the research in the field of wine tourism in Bulgaria. In this article, wine tourism is viewed as part of alternative tourism on one hand, and on the other - in this specific instance - as exhibiting the specific features of the so-called "festival tourism". The scientific material is based on a survey conducted at a festival of wine and cultural heritage.
\end{abstract}

Key words: wine tourism, festival tourism, alternative tourism, a festival of wine and cultural heritage, Bulgaria

\section{INTRODUCTION}

There is an observable trend nowadays for strong growth of tourism activities in various destinations, in which the alternative forms of tourism have increasing importance. Contemporary tourists are attracted by sites and economic activities exhibiting specific peculiarities and features. The determining factor in the identification of alternative tourism types turns out to be motivated as the starting point in the process of taking the decision for practicing such tourism. Natural objects, cultural-historical sites or specific wares could attract interest, as well as develop and promote a specific settlement to the point of becoming a popular destination.

\footnotetext{
*Correspondence to: Blaga Stoykova, Department of Regional Development, Faculty of Economics, Trakia University, Student's Campus, 6000 Stara Zagora,Bulgaria,blaga.st@gmail.com
}

Food and drink are an important part of the tourist product. The specifics of the local cuisine and alcoholic beverages are just as popular among tourists as natural and cultural-historical sites. Wine enjoys special interest as well, as it is invariably tied to human history from ancient days to modern times. It is deeply rooted into the way of life of Bulgarians, and is an important element of the nation's consumer basket even today. Wine consumption, in accordance with data by the National Statistics Institute (NSI) (1), has reached relative stability, with an annual variation of 5.5 to 4.3 litres per household member (Annual data on household consumption) (2). The modern lifestyle and the establishment of gourmet culture have urged many people to look for more in-depth information, for opportunities to "enrich" their palate by trying new and unfamiliar wines. This is, to a great extent, the primary motivation for 
the sustained development of the so-called "wine tourism."

\section{LITERATURE REVIEW}

World literature contains information on numerous studies in this field, yet they are very fragmented in nature. Researchers in the field have stated that "when viewed from a marketing perspective emphasis is likely to be placed on the determination of the experiences sought by potential and actual wine tourists" (3). In an earlier study from 2000, Getz claims that at least three primary actors could be discerned: "that of wine producers, tourism agencies (representing the destinations) and consumers" (3).

Other authors believe that the type of tourism is determined by specific tourist activities, by the goals and motivations for the trip. The same categorizes wine tourism as a form of special goal-oriented tourism. They consider that wine and tourism have been inseparable for many years, with this being just one of the reasons for the emergence of wine tourism. They define it as "visitation to vineyards, wineries, wine festivals and wine shows for which grape wine tasting and/or experiencing the attributes of a grape wine region are the prime motivating factors for visitors" (4). In this case, visiting vineyards, wine cellars, wine festivals and a wine show related to sampling and/or experiences related to the vineyard/wine-producing region are the main motivating factors for the visitors.

Wine tourism was viewed as an important economic phenomenon in the mid-1990's. The rising number of people interested in wine and its production exhibited relatively high values (3). In this sector of the tourism market, consumers are defined by a medium to higher level of education and personal income, and they wish to experience a pure sensation through personalized tourist services. Visitors have requirements and pay specific attention to the wine's flavour, the overall quality, the winery's cleanliness, and the complex presentation of the service. They prefer to travel in small groups (5).

In 2000, Getz added that "wine tourism is a trip related it the attraction of wineries and of a winegrowing area, a kind of market niche and way of destination development, and it is an opportunity for direct sales and a marketing opportunity for the wine industry" (6). Other authors tried to
ZHELEVA V., et al. establish a critical assessment in the wine tourism sector, considering that the motivation element was important. Based on this criterion, they arranged the European authors who had worked on this topic in a table format (7).

According to some Bulgarian authors wine tourism is defined as specific. This allowed tourists to get acquainted with the vineyards and viticulture, by observing the specific methods and ways of caretaking, including pruning of the vines and collecting grapes in the visited regions, as well as the history, traditions and wine, the production methods and the wineries (cellars and larger wine factories). As a part of their vacation, tourists get to know various wines and stronger alcoholic beverages through sampling, rituals and festivals devoted to wine, with these events often being combined with rich folklore programmes and entertainment (8).

Others examined the "traditional ties between wine and tourism" and aimed to describe "the origins, essence, typical forms, and role of wine tourism as an effective alternative to mass tourism" (9).

A scientific study from the same period suggested that wine tourism is simply an alternative to satisfy people's yearning for adventure and romance. Wine sampling during seminars and winery visits is now offered in many areas and regions. This kind of tourism, however, could only work smoothly when there is efficient coordination and good cooperation between tour agencies and wine production companies. Furthermore, success also requires the availability of proper infrastructure. The article analyses a successful model for wine tourism on a local level, which could be used as a model and be applied in other regions of the country. It is mentioned that Bulgaria currently has not developed its potential in the field of wine tourism, and more "aggressive" measures need to be taken in this regard (10).

The national strategy for the development of viticulture and wine production in the Republic of Bulgaria (2005 - 2025) places a significant emphasis on the development of wine tourism in the country. Among the measures for affirming the authentic image of Bulgarian wine are the following: capitalising on the opportunities for wine tourism through its stimulation, in order to 
increase the profitability of wineries, as well as a shared advertising campaign with tour operators to promote wine tourism, supported by the appropriate infrastructure and skilfully organised facilities for sampling and recreation. There is also a focus on the development of a complete and purposeful public strategy for advertising the unique nature and the possibilities of the Bulgarian wine industry. This could be achieved by creating conditions for advertising Bulgarian wines, creating a new image, including: providing funding for fostering the sales of Bulgarian wines and building up their good reputation in the country. Of particular importance is the organisation of advertising and promotional events, and the increase of Bulgarian participation in world wine forums and institutions (11).

A survey from 2011 presented data, which indicated that the tourists practicing wine tourism's choice of destination was affected the most by the quality of the offered product, and to a lesser extent by the ease of access to the site, followed by the category of the lodgings (12). The survey respondents most commonly visited sites related to wine tourism once per year or did not practice this type of tourism at all. With regard to the conditions for the development of wine tourism in Bulgaria, $73 \%$ of the respondents thought that such conditions existed, while only $3 \%$ thought they did not, while $2 \%$ said they could not answer. The preferred season for visiting sites related to wine tourism is the winter, followed by the fall. Spring and summer are marked by the same levels of interest (12).

A study devoted to the development of wine tourism and wine production in two Bulgarian regions (Danube and Thracian regions) traced the history of organized visits to wine cellars and samplings of high-quality wines by tourists. Enotourism in Bulgaria is believed to have begun with visits to "Vinprom Lyaskovets" where foreign tourists were invited and offered Bulgarian wines. The authors noted that the changes occurring in the country's economy after 1989 marked the beginning of a new stage in the development of Bulgarian wine production, gradually beginning to change the image of wine industry as a whole, with interest in wine tours growing after 2001 when several thematic clusters and wine tourism rays were developed
ZHELEVA V., et al. (13). Within the cited study, founded upon a survey among respondents from the Danube and Thracian vineyard-wine regions, which are registered as wine producers and entered into the Registry of categorized tour destinations and/or a consolidated municipal centre as places for accommodation or dining/entertainment establishments, it was made clear that wine tourism was actively developed in both regions, with the leading service being sampling at a specially built sampling hall, where tourists could taste between 3 and 7 proprietary wines. The least offered services turned out to be the combinations of the wine tour with alternative activities, such as sports, cultural-historical or social events (13). The country's primary strategic documents also take into consideration this type of tourism. The National strategy for the development of viticulture and wine production in the Republic of Bulgaria (11) gives special attention to the development of wine tourism, which is, on one hand, related to capitalizing on the possibilities of this type of tourism through its stimulation, in order to improve wineries' profits, and on the other hand an advertising campaign in cooperation with tour operators aimed at promoting wine tourism is indicated as a guarantee for success. Accomplishing this goal, of course, requires building up a proper infrastructure and skilfully organized complexes for sampling and relaxation. The strategy reviews only the sector's strong and weak aspects, while also setting goals towards developing and fostering wine tourism. For the sake of achieving this, "the possibilities for wine tourism through its stimulation and improvement of wineries' profitability" are capitalized on (11).

The Wine and Alcoholic Beverages Act mentions five viticulture regions within the country: North region "Danube Plain," East region "Black Sea," Sub-Balkan region "Rose Valley," South region "Thracian Lowlands," and Southwest region "Struma Valley" (14).

The highest number of wineries can be found in the South viticulture region "Thracian Lowlands," followed by the Danube Plan region, while the lowest number is in the Sub-Balkan region, which is also the smallest in terms of territory (15).

A dissertation dedicated to wine tourism differentiates the main sites of tourist visits in a 
viticulture-winery region, which have been determined to be the core of the wine tourism product. These are vineyards, cellars, enoteche, and viticulture museums. The other participants defined in the scheme are the complementary core of the wine tourism product. These are the stakeholders that include the typical subjects of tourism - hotels and guests houses, restaurants, taverns and bars, souvenir shops, culturalhistorical sites, ethnographic complexes, etc. (16).

Even though the product of wine tourism is primarily located within the viticulture-winery regions, a number of expos, festivals, and events devoted to wine and alcoholic beverages have also been on the rise. Festivals related to wine and foods are particularly popular in our country. It may therefore be said that festival tourism falls within the scope of wine tourism, due to the fact that it aims to familiarise its visitors with wine, wine producers and wine regions. Events of this type gain greater importance and significance in the life of the contemporary tourist and turn into a modern alternative for spending one's free time. The wine festival is described as a special event, and its proper organisation, and choice of a suitable location could turn it into an event of regional, as well as national prominence. Nowadays, wine festivals are turning into a unifying factor between the wine industry and the tourist sector. Successful festivals are turning into a trademark of the respective region, and an attractive destination sought after by visitors.

Wine production has deep roots within the Stara Zagora region. The region is part of the so-called South viticulture region "Thracian Lowlands." Several wineries are established here: the "Midalidare" Complex in the village of Mogilovo, Chirpan Municipality (has two cellars and "produces wines in small batches with a strong character"); the Chateau-Hotel "Trendafiloff" located near the town of Chirpan; the Zaara Estate Winery (has a sampling hall); the Svoboda Winery, located in the village of Svoboda, Chirpan Municipality; Domain Menada Winery, which is one of the oldest wineries in Bulgaria, founded in 1901 and is among the fastest-developing companies on the Bulgarian wine market; the Better Half Winery, which is located in the village of Zmeyovo, Stara Zagora region (a family winery based on the
ZHELEVA V., et al. principle of the classic garage cellar - "where every vessel has its own unique history"), and the Oryahovitsa Winery, located in the village of Oryahovitsa, Stara Zagora region, exporting a large part of its produced wine, mainly to Austria, Germany, Russia and Great Britain.

The city of Stara Zagora is the administrative centre of a region with many centuries of traditions in the field of wine production, and, therefore, mechanisms to organize a forum with an emphasis on wine production have expectedly been sought over the last few years, in a combination with culinary masterpieces, against the background of a remarkable historical heritage. It is interesting to note that since the beginning of the current decade, the Festival of Wine and Cultural Heritage Avgustiada has been organised and conducted in the building of the Regional Museum of History in Stara Zagora. The organisation is assisted by the private sector, municipal authorities, and NGO's. This is a typical example for a special event whose main goal is to create opportunities for meetings between the best wineries of Bulgaria, which can present their products and introduce the visitors to it. International participation of wine producers from West European countries, as well as close Balkan neighbours, has become a leading trend. An innovation from recent years is putting a focus on gourmet culture, including the wine production of certain countries. Leading sommeliers organize master's classes. Good schools in the field are also presented. The event is accompanied by numerous additional initiatives, including the election of an Avgustiada Queen. The event finale is grandiose and features musical galas at the State Opera Stara Zagora (2). Apart from wine producers, representatives of the food production sector, industry, state institutions, as well as people who appreciate cultural heritage, also take part in the festival. The festival organisers have shared that "in recent years, the wine and culinary culture in Bulgaria have exhibited impressive development, and events of this nature enjoy high levels of interest. The forum in Stara Zagora, with its unique and special atmosphere, is shaping up as a leader in Bulgaria's wine calendar, also with a great potential to attract international participants." The event received considerable general and specialised, regional and national media coverage. 


\section{METHODOLOGY}

For the purposes of this study, and for gathering factological information on the situation in which wine tourism has a particular intensity in a given region, we have used a field survey method. The target group covers people over 18 years of age tourists who attended the "Festival of Wine and Cultural Heritage Avgustiada 2018" in the city of Stara Zagora within the period of 13-14 October 2018.

The survey method includes statistical, historical, comparative-descriptive, and regional analysis. The most significant for this study is the direct standardized interview on the day of the respective event. The survey is voluntary and anonymous. The questionnaire consists of 16 questions, 15 of which are closed and one is open. Participants have given more than 1 answer to some of the closed questions, which is why the percentage total exceeds $100 \%$ after the processing of the data. All statistical analysis in this study has been calculated at a statistical error of $\mathrm{p}<0.05$, which has been defined in the statistical software. Results with an error greater than 0.05 have not been interpreted in the study. The survey has reached 181 respondents.

\section{RESULTS}

Data used in this study were obtained from an original survey on the Festival of Wine and Cultural Heritage Avgustiada 2018, performed during the three days of the event. The survey took place at the festival site - Regional Historical Museum, Stara Zagora. The obtained information was representative, and the sample was randomly chosen among participants and guests of the festival.

The majority of respondents were Bulgarian citizens $-81.77 \%$, while foreign participants comprised $18.23 \%$ of the entire survey sample. A trend to increase of visits from foreign tourists was noted (2). An age-related distinction could not be made, as results were almost similar. The highest share was of persons aged 41 to 50, amounting to $28.18 \%$. They are followed by respondents identified in the group over 51 years of age, being $26.52 \%$, while $24.86 \%$ of the surveyed indicated that they were aged between 18 and 30 years, and last came $20.44 \%$ of the respondents, who were in the 31 to 40 years age range. It was found out that most of visitors were employed, with higher educational degree and
ZHELEVA V., et al. income about and more than 1000 BGN. Testaments to this are the results from the survey. When reviewing the responses to the survey. On the question of identifying the visitors' social status, $88.40 \%$ of them noted that they were employed at the time of the study. Only $11.60 \%$ of the respondents were retired, and $3.31 \%$ were students. Regarding the degree of education of the visitors at the Festival of wine and cultural heritage Avgustiada 2018, the following results were observed: $83.43 \%$ claimed to have higher education, while $16.57 \%$ had secondary education. None of the respondents marked "primary education" as their answer. This indicates that in this kind of events the majority of visitors are highly educated people who have interests related to wine, wine production, culinary, and the cultural and historical heritage of this region. As for the monthly income of the respondents, we observed that the largest share was of the persons earning more than BGN 1000 per month, which is $56.91 \%$ of the surveyed. They are followed by the persons with a monthly income of BGN 500 to BGN 1000 (33.15\%). Lastly, $9.94 \%$ of the respondents indicated that their monthly income was between BGN 300 and BGN 500. No one indicated income below BGN 300 per month.

The analysed results from the gender identity question indicated that the share of surveyed women was higher $-68.51 \%$ vs $31.49 \%$ men. The main part of respondents comprised local citizens of Stara Zagora $-66.30 \%$. They were included in the survey because of their aptitude towards entertainment and spending money for purchase of different national and foreign wines, something that they would not do in working days. They were followed by groups of visitors from other settlements and business representatives, with $23.77 \%$ and $13.26 \%$ respectively.

According to the results, $49.72 \%$ of respondents participated in wine tourism two or three times in a year. They were followed by those participating only once in a year $(23.20 \%)$ and more than 5 times on an annual basis (20.44\%). In aforementioned survey from 2011, the majority of respondents visited sites connected to wine tourism once per year or did not visit such sites at all (12). It should be noted that the interest to thematic journeys associated to wine or visits of 
similar events has significantly increased throughout the years and was among motivating factors affecting leisure time spending (Figure 1).

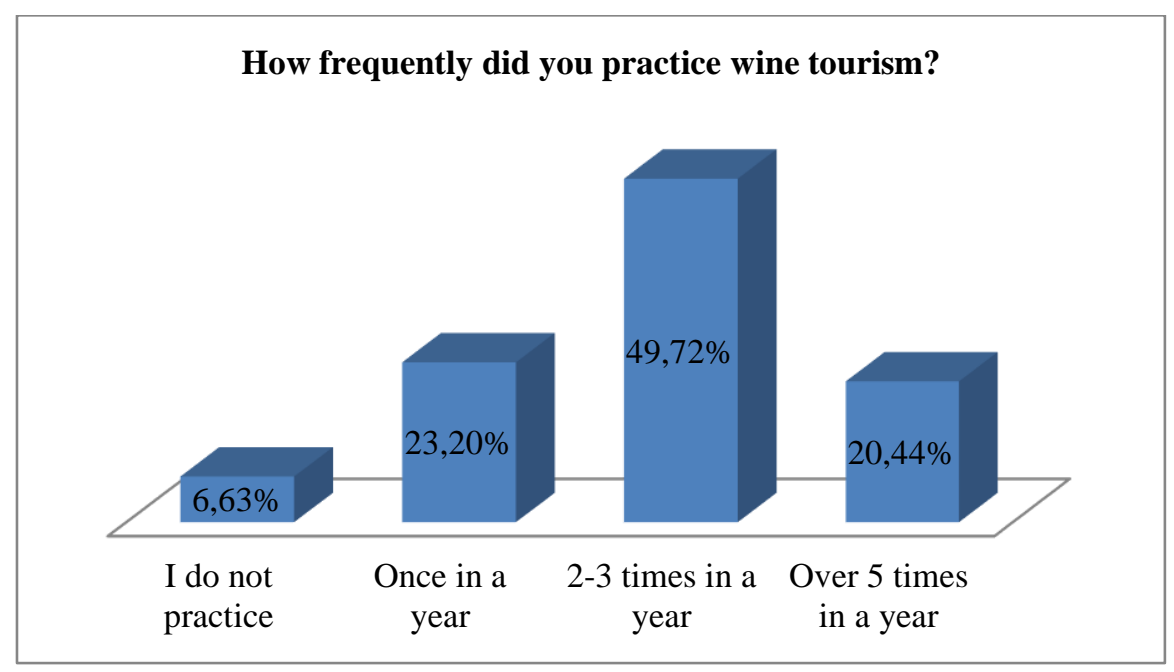

Figure 1. Frequency of wine tourism practice

Respondents nominated autumn as the most preferred season $-70.17 \%$, but this type of events was practiced also during the other seasons, although less actively (Figure 2). The comparison with the 2011 survey gave advantage to winter as season of preference for visiting wine tourism events, followed by autumn. Spring and summer were equally preferred (12).

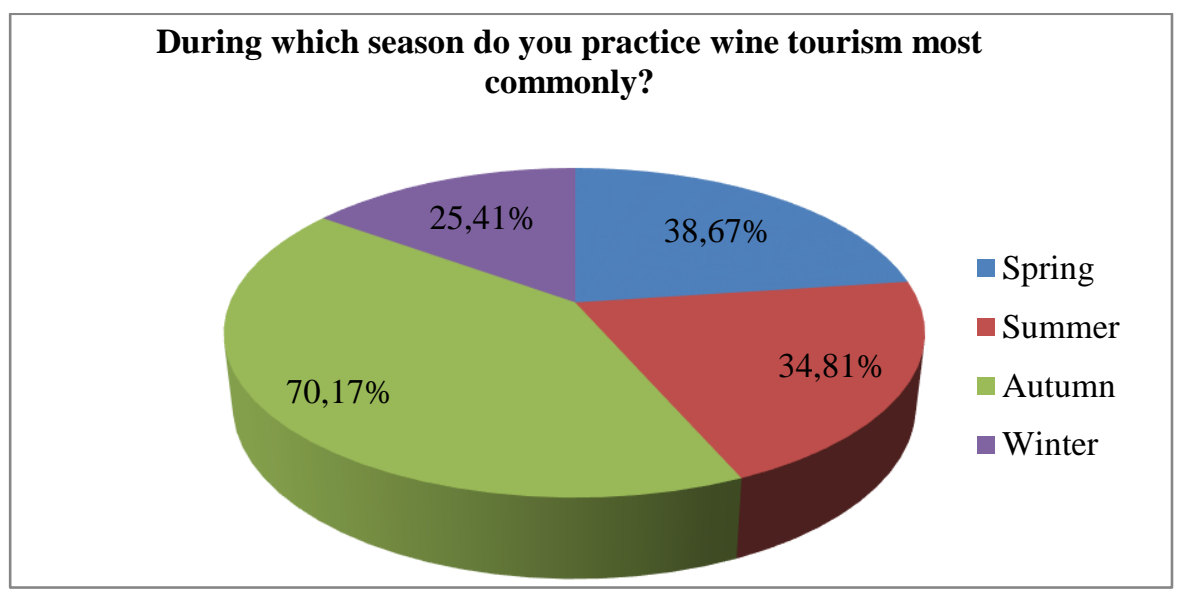

Figure 2. Preferred season for wine tourism

The further analysis of raw data made clear that love to wine prevailed among motives for such visits, as $66.30 \%$ of respondents determined themselves as "fans of wine". This group was followed by the group of visitors seeking social contacts $(24.86 \%)$. Of course, such events are visited also by representatives of the business and by people professionally engaged with wine and wine production $(17.13 \%)$ (Figure 3). 


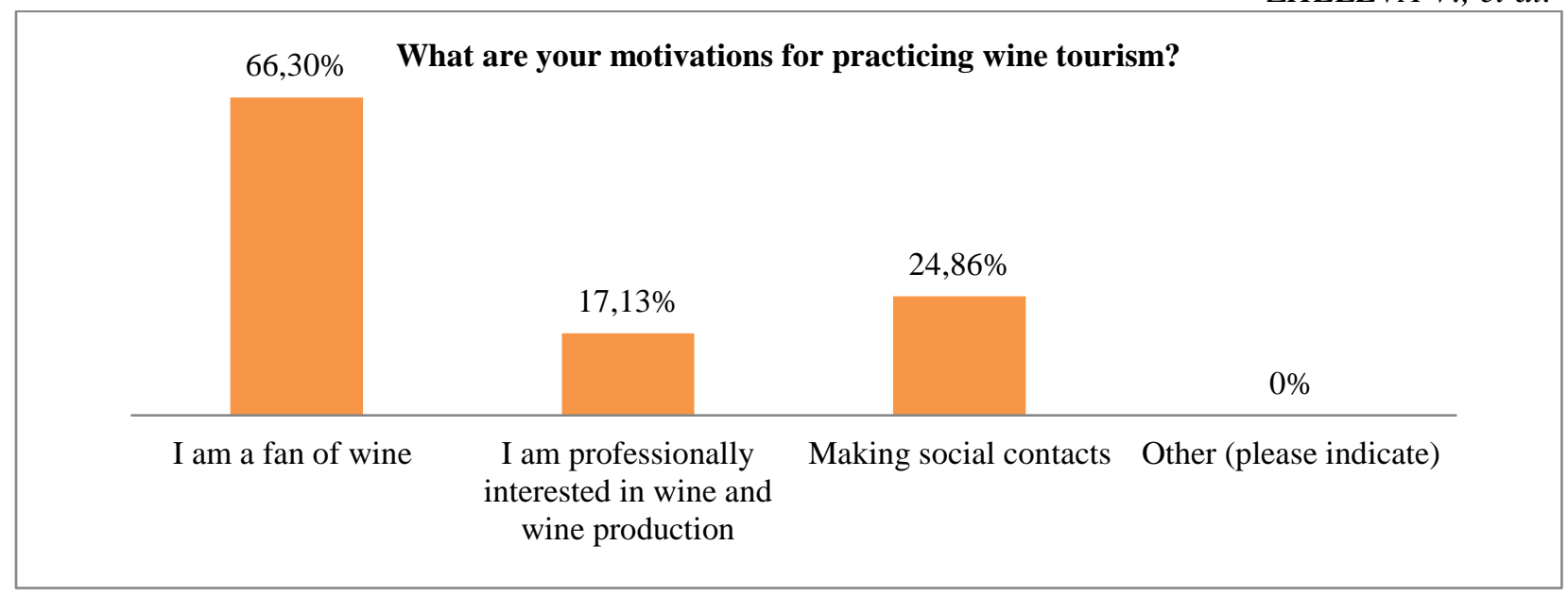

Figure 3. Motivations for practicing wine tourism

Figure 4 and 5 illustrate the budget of visitors to such type of events, including money spent for wine purchase from the festival site. Fig. 5 shows that $88.40 \%$ of visitors spent up to BGN 250; the share of those exceeding that sum was low. The budget included money for purchase of wine. The detailed analysis showed that $35,36 \%$ of respondents spent up to BGN 50 for wine while
$28.73 \%$ - up to BGN 20. A small proportion has spent more than $50 \mathrm{BGN}$ - only $14.92 \%$. A significant proportion of respondents did not buy wine at all at the festival $-20.99 \%$.

The presented data confirmed that in general, visitors were not inclined to purchase additional amounts of wine apart from samplings at the time of the event.

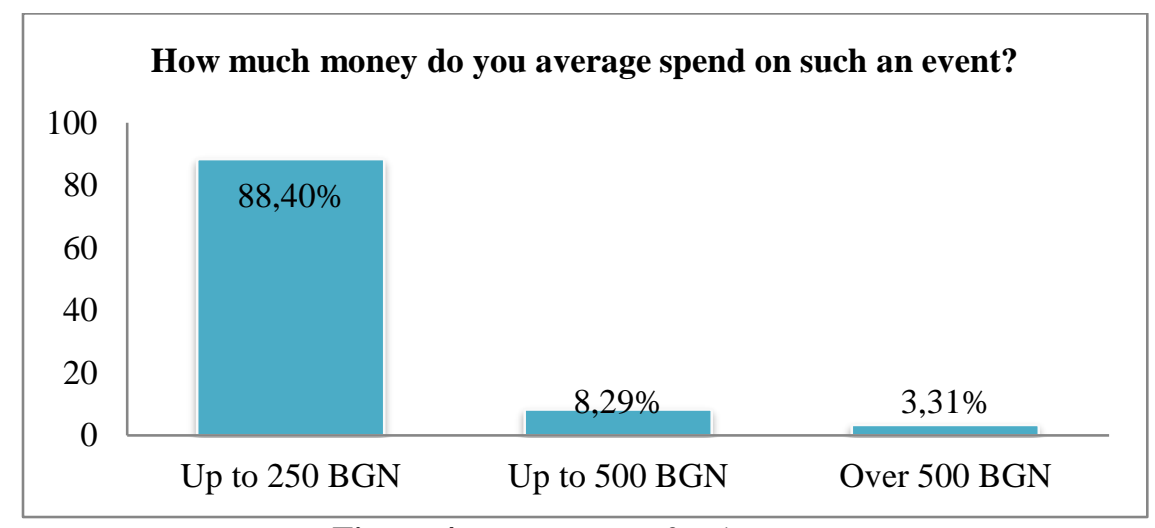

Figure 4. Money spent for the event

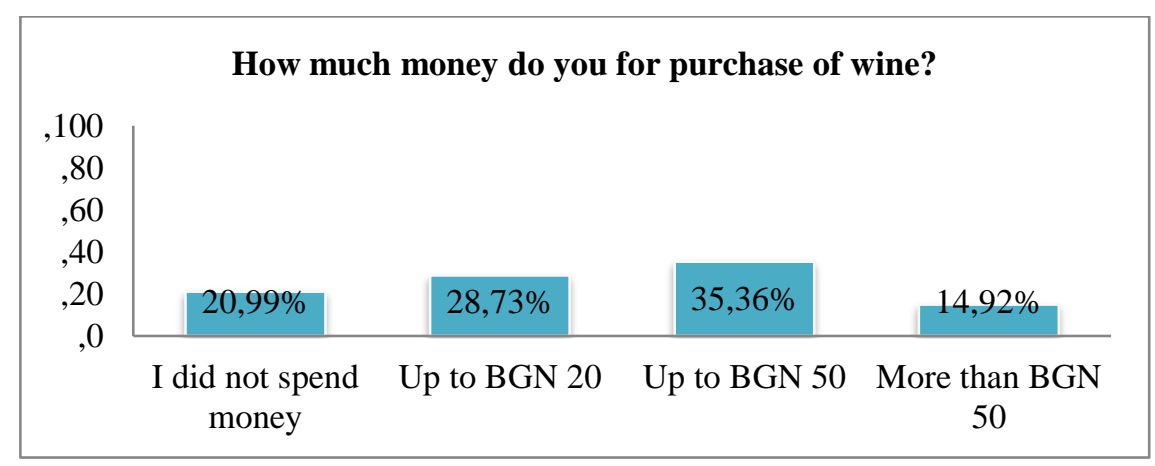

Figure 5. Money spent on purchase of wine 
According to $85.08 \%$ (Figure 6) of respondents, the development of wine tourism did not pose any problems for the local people. A substantial proportion $(99.45 \%)$ affirmed that local people would rather benefit from increased number of tourists and region's attendance (Figure 7). Only
ZHELEVA V., et al. $3.31 \%$ believed that this could have adverse impact (including on the environment and infrastructure) (Figure 6). Less than 1\% (0.55\%), being foreign citizens, had no opinion on the development of the region.

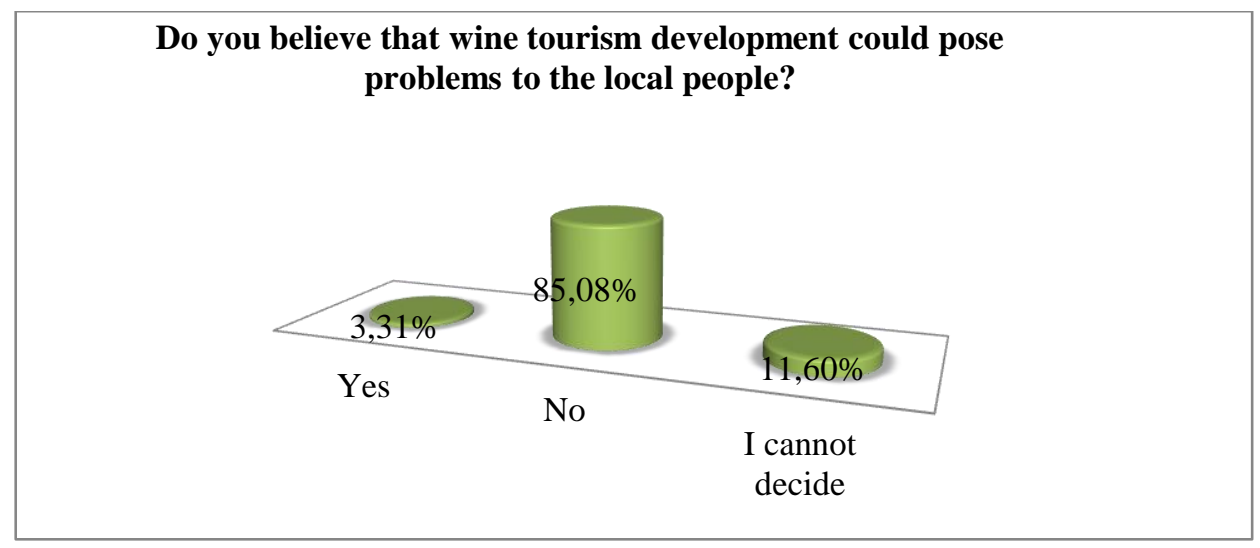

Figure 6. Wine tourism development and local people

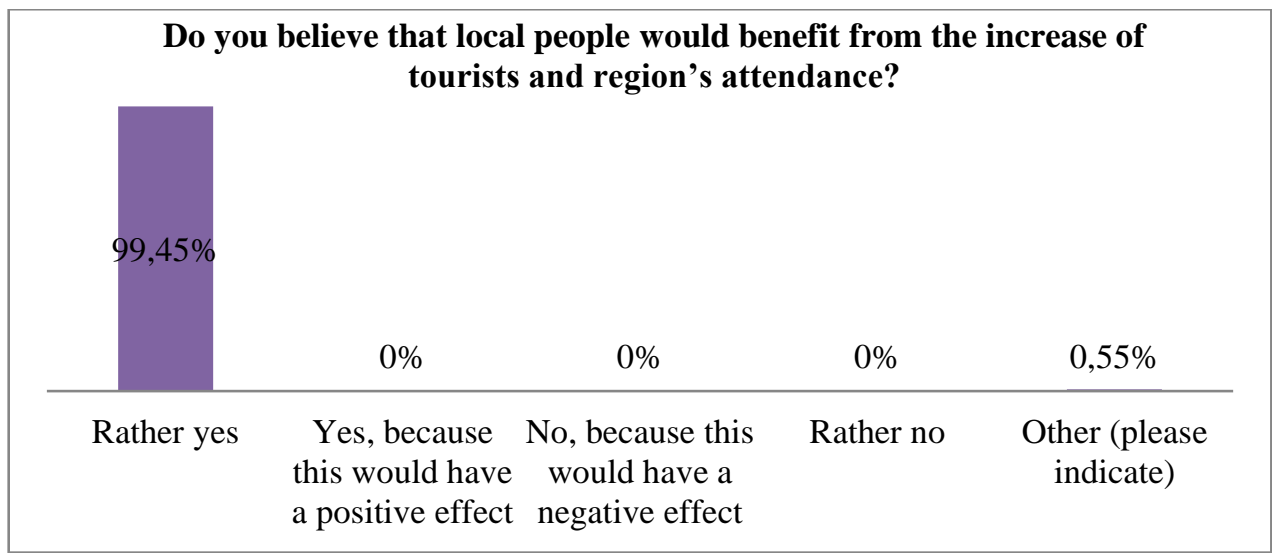

Figure 7. Benefits from wine tourism development in the region

\section{CONCLUSIONS}

- The Festival of Wine and Cultural Heritage Avgustiada 2018 has the potential to become a special national event, attracting enough tourists, both fans of wine and fans of cultural heritage in general;

- It is difficult to calculate the economic benefits for the city of Stara Zagora and the region as a whole because the wine producers that present their produce at the festival earn the main dividends from the event. There are also intangible benefits and the accumulation of intangible assets, which, coupled with a proper policy for building up the brand, could place Stara Zagora on the tourist map of festival cities that offer wine samplings and gourmet pleasures.
- Tourism, as a major driving force in the economy both at the national and local level, is one of the major tools for regional development. For Stara Zagora, it is not only a source of funds from the sale of local goods and services, but also an appropriate field for opening new jobs in sectors related directly or indirectly to tourism, both in big and small settlements. Wine tourism is yet an empty niche in the country, with significant potential for development. A Little more effort from the part of wine producers and the tourism industry is needed to bring this endeavour to success.

- It can be concluded that the amount of funds that tourists who participated in the survey tend to spend is not affected in any way by their 
gender identity. The age and monthly income of the respondents have no relation to the amount of funds they set aside for the purchase of wine and wine products, but they prove to be a key factor in determining the amount of funds that are set aside for the event as a whole.

\section{REFERENCES}

1. Annual data on household consumption, NSI, 2019

2. Economic Yearbook, Stara Zagora Region, Bulgaria - 2019 (Annual edition, Number 18)

3. Brown, G., Getz, D., Critical success factors for wine tourism regions: a demand analysis. Tourism management, 27, 46 - 158, 2006

4. Hall, C., Sharples, L., Cambourne, Br., Macions, N., Wine Tourism Around the World Development, management and markets, 3-4, 2000

5. Dodd, T., Opportunities and pitfalls of tourism in a developing wine industry. International Journal of Wine Marketing, 7(1), 5 - 16, 1995

6. Getz, D., Explore wine tourism: management, development, destinations, Cognizant, New York, 5, 2000, cited per Iglesias, M., Navarro, M., Wine tourism development from the perspective of family winery, Cuadernos de Turismo, 34, 415 - 418. 2014

7. Guzmán, T., Rodríguez, A., García, J., Profile and motivations of European tourists on the Sherry wine route of Spain, Tourism Management Perspectives 11, 63 - 68, 2014

8. Alexieva, Y., Stamov, St., Wine tourism, Plovdiv, 4, 2004

9. Neshkov, M., Wine and tourism - from tradition to present day, Wine tourism tradition and modernity, Black Sea Tourist Forum, Varna, 12, 2009

10.Stoykova, B., Successful practices in wine tourism following the example of Oryahovitsa
ZHELEVA V., et al. winery in Stara Zagora region, Trakia Journal of Sciences, Vol. 7, No. 3, 74 - 80, 2009

11. National strategy for the development of viticulture and wine production in the Republic of Bulgaria (2005-2025), Sofia, 2004

12.Dyankova, D., Blagoeva, I., Yordanova, S., Yalamov, S., Nikolova, Ya., Berberova, R., Condition and development of wine tourism in Bulgaria - results from survey, Ecologisation, NBU, 22 - 31, 2011

13.Goranova, P., Tsvetanova, E., Examining the role of wine tourism in the sustainable development of regions producing regional wines in Bulgaria (Danube and Thracian), Almanac of Scientific Studies. Tome 25, part II, 167 - 197, 2018

14. Wine and Alcoholic Beverages Act, published in State Gazette issue 45 dated 15 June 2012, last amended in State Gazette issue 98 dated 27 November 2018

15.Peycheva, A., Territorial coordinance of the wine vineyards in Bulgaria in the context of the wine-growing regions in the country, Agribusiness and rural regions - economy, innovation and growth Conference proceeding Scientific and practical conference, organized by The Department of Agricultural economics at University of Economics - Varna in cooperation with The Bulgarian Association of Agricultural producers 12-13 October 2017, V., 137 - 145, 2017

16.Dimitrov, V., Raising the competitive advantage of the wine tourism product through diversification, Self-referral to dissertation for earning the educational and scientific degree of $\mathrm{PhD}$ in the scientific field of "Economics and Management" (Tourism), UNWE, 2014. 